\title{
Wegener's granulomatosis with
}

\section{abnormal arterial pressure response to the Valsalva manoeuvre}

\author{
A. M. HolmeS \\ B.Sc., M.B., M.R.C.P.
}

\author{
T. B. Stretton* \\ M.B., M.R.C.P.
}

Manchester Royal Infirmary

THE DISORDER known as Wegener's granulomatosis (Klinger, 1931 ; Wegener, 1939) has certain features akin to polyarteritis nodosa and may be one manifestation of this disease, with its wide spectrum of presenting clinical abnormalities. The diagnostic triad of Wegener's granuomatosis comprises necrotizing granulomata of the respiratory tract, generalized vasculitis and glomerulitis (Godman \& Churg, 1954). Typically, a middle-aged man presents with a destructive, ulcerated granuloma in the nasal air-passages and later develops similar lesions in the lower airways and lung parenchyma; renal abnormalities usually develop and death from uraemia is common. Systemic arteritis may involve the nervous system, most commonly producing a peripheral neuropathy of the 'mononeuritis multiplex' variety (Drachman, 1963 ; Stern, Hoffbrand \& Urich, 1965), and skeletal muscular wasting may be secondary to this, to disuse atrophy, or to necrotizing myopathy (Stern et al., 1965). The prognosis is poor: death frequently occurs in a few months (Walton, 1958), though survival for several years has been described (Fahey et al., 1954 ; Evans \& Halley, 1963).

The patient described below developed such an illness with necrotizing lesions of the respiratory tract, digital arteritis, a proximal myopathy of the limbs, and severe congestive cardiac failure. In place of the expected 'square-wave' response of his arterial pressure to a Valsalva manoeuvre, there was a response of the type found in denervation of the baroreceptors or blockade of the normal reflex response to a falling stroke output of the heart.

\section{Case report}

A previously healthy 56-year-old man presented with sudden pallor and spontaneous pain in all the fingers of his left hand and was found to have some wasting of the pulp of the finger tips, particularly in the middle finger. The next month,

\footnotetext{
*Present address: Royal Victoria Infirmary, Newcastle upon Tyne.
}

whilst on holiday in the South of England, he suddenly became ill and developed pain in the left side of his chest, breathlessness and fever. He coughed up a little blood-stained sputum. He was admitted to hospital and treated with antibiotics for what was at first thought to be pneumonia. About 10 days after admission his arms and legs became very weak and he developed generalized oedema. Diuretics produced only a poor diuresis. Steroids were then given and his fever rapidly remitted, whilst his oedema also improved. He remained ill, however, and as he was still unfit to be discharged 3 months later, he was transferred to Manchester Royal Infirmary in order to be nearer home.

At this stage he had developed a bleeding, encrusted ulcer in his nose and also had a transient generalized erythematous eruption of his skin.

On examination he was oedematous with a jugular venous pressure of $5 \mathrm{~cm}$. He was in sinus rhythm (rate $100 / \mathrm{min}$ ) with frequent ectopic beats. BP, $160 / 100 \mathrm{mmHg}$; cardiac impulse, $2 \mathrm{~cm}$ outside the mid-clavicular line; no abnormalities on auscultation. Crepitations were heard over the lower lobes of both lungs. The liver edge was palpable below the right costal margin. He had extensive muscular wasting with weakness, particularly of the proximal limb muscles; there was no fasciculation. Tendon reflexes were present and the plantar responses were flexor. He had no sensory impairment. There were a few scattered superficial septic spots on his skin. He had a small ulcer on the hard palate and a granulomatous ulcer about $2 \mathrm{~cm}$ in diameter which had perforated his nasal septum. This was examined by Professor V. F. Lambert who considered the lesion to be characteristic of Wegener's granulomatosis. He also had several small atrophic lesions on his finger tips consistent with infarction due to digital arteritis.

Steroid therapy was continued, the dosage of prednisolone being increased temporarily to $80 \mathrm{mg}$ daily (in divided doses). Diuretics were continued. 
He was digitalized. He remained afebrile and his muscular power slowly improved. His oedema became less but never disappeared. His skin lesions all healed; the ulcer on his palate did likewise and there was partial healing of the granulomatous ulcer in his nose. Six months after first admission to hospital he was discharged home on maintenance therapy with prednisolone, digitalis and thiazide diuretics. He still had residual myopathic weakness but was able to walk unaided; he was slightly breathless with the limited exertion of which he was capable and always had some ankle oedema. For 7 months he maintained fair health but then began to deteriorate again with recurrence of his muscular weakness, increased breathlessness and development of gross oedema and ascites. There was no response to treatment this time and removal of oedema fluid by Southey's tubes was of no benefit. He died in gross congestive cardiac failure some 15 months after the onset of symptoms.

\section{Investigations}

$\mathrm{Hb}, 12 \cdot 3 \mathrm{~g} / 100 \mathrm{ml}$; WBC, $12,600 / \mathrm{mm}^{3}(88 \%$ neutrophils ; $6 \%$ lymphocytes ; $5 \%$ mononuclears ; $1 \%$ eosinophils); ESR, $50 \mathrm{~mm}$ (Wintrobe) on admission falling to normal during his period of relative 'remission'. Blood urea was $47-55 \mathrm{mg} / 100$ $\mathrm{ml}$ throughout the time he was under our observation, rising terminally to $126 \mathrm{mg} / 100 \mathrm{ml}$. Serum electrolytes, including calcium and phosphate, were normal. Serum albumin, $2.5 \mathrm{~g} / 100 \mathrm{ml}$; globulin, $3.6 \mathrm{~g} / 100 \mathrm{ml}$; electrophoresis showed an increase in $\alpha_{2}$ and $\gamma$-globulins. During his months of 'remission' the serum albumin rose to $3.6 \mathrm{~g} / 100 \mathrm{ml}$. Serum cholesterol, $190 \mathrm{mg} / 100 \mathrm{ml}$; bilirubin, $0.5 \mathrm{mg} / 100 \mathrm{ml}$; thymol turbidity, 2.7 units; alkaline phosphatase, 8.0 units $/ 100 \mathrm{ml}$; aldolase, 14 units ; glutamic oxaloacetic and pyruvate transaminases were 6 and 16 units/ml respectively. Antistreptolysin ' 0 ' titre was 50 Todd units. LE cells were not found, anti-nuclear factor was not detected and sheep cell agglutination test was negative. WR negative. Urinary protein loss varied but was always less than $0.5 \mathrm{~g} / 24 \mathrm{hr}$ and no abnormality was found on microscopy of the urine.

A chest radiograph showed numerous patchy opacities in the lower zones of both lungs and slight cardiomegaly. The right maxillary antrum was seen to be opaque on an X-ray of the skull.

The vital capacity was 3.14 litres $(82 \%$ of predicted). Electromyography showed a myopathic pattern with normal nerve conduction time. An electrocardiogram (before digitalis was given) showed slight ST depression and flattened $T$ waves in left precordial leads; ventricular ectopic beats were frequent. The circulatory response to a Valsalva manoeuvre was abnormal (see Fig. 1).

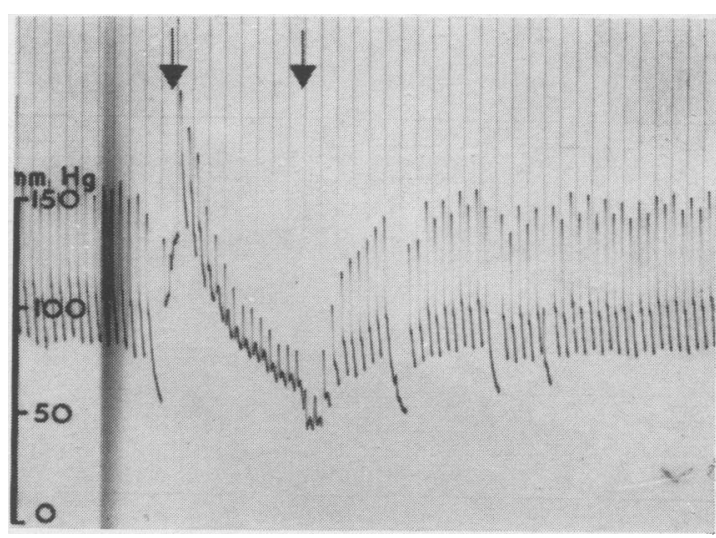

Fig. 1. The systemic arterial pressure response to Valsalva's manoeuvre. Intrathoracic pressure raised between arrows. Time interval in seconds.

\section{Necropsy}

Necropsy (Dr A. Garner) did not reveal evidence of active arteritis. Digital vessels showed medial calcification and some destruction of the elastica which was considered to be compatible with past arteritis. There was diffuse fibrosis in the lower lobe of the left lung with a patchy chronic in flammatory cell infiltration. The kidneys showed mild fibrosing endarteritis. There was cardiac enlargement wtih left ventricular hypertrophy and right ventricular dilatation; there was coronary atherosclerosis and evidence of posteroseptal infarction (estimated to be 1 week old). There was chronic venous congestion of the liver. An ulcer of the soft palate was infiltrated with chronic inflammatory cells but no granulomatous or arteritic lesions were seen. The findings were mostly non-specific and the absence of active arteritis was attributed to steroid therapy.

\section{Discussion}

The clinical features in this patient were those of the syndrome of Wegener's granulomatosis. Although characteristic histological lesions of the latter were not demonstrated it is felt that this does not exclude the diagnosis since the patient had been on high dosage corticosteroid therapy, from which he appeared clinically to benefit, with partial healing of the perforating ulcer of his nasal septum, complete healing of his skin lesions, resolution of the digital arteritis, improvement in the myopathy and a return of his ESR to normal.

The point of particular interest was the patient's abnormal circulatory response to the Valsalva manoeuvre (Fig. 1). This was done because for some time there was debate whether his raised venous pressure and oedema were in part due to hypoalbuminaemia $(2.5 \mathrm{~g} / 100 \mathrm{ml})$ and consequent 
hypervolaemia (from presumed secondary aldosteronism) or were entirely manifestations of congestive cardiac failure. Progression of his illness resolved any uncertainty on this point because the low serum albumin returned to normal $(3.6 \mathrm{~g} / 100$ $\mathrm{ml}$ ), yet the signs of heart failure persisted and latterly became very gross. The pathogenesis of the cardiac failure is uncertain. Clinically the features were those of a cardiomyopathy and there was nothing in the natural history to suggest underlying coronary artery disease. Post-mortem examination, however, revealed the presence of coronary atherosclerosis with a recent posteroseptal myocardial infarction. It is therefore possible that the congestive heart failure was primarily due to the coronary artery disease rather than to myocardial disease associated with the Wegener's granulomatosis. In either event one would expect a squarewave response to the Valsalva manoeuvre.

During the phase of raised intrathoracic pressure in a Valsalva manoeuvre the stroke output of the normal heart diminishes (vascular constriction as a result of the falling stroke output helps to maintain the mean arterial pressure) but in cardiac failure the stroke output does not vary acutely with changes in venous return; this leads to the 'squarewave' pattern of arterial pressure response (Sharpey-Shafer, 1955). This patient was undoubtedly in heart failure yet the pulse pressure fell considerably during the period of raised intrathoracic pressure (see Fig. 1). When the Valsalva manoeuvre was terminated there was a gradual return of arterial pressure to its initial level and not the normally rapid overshoot to temporarily higher levels. This suggests that vasoconstriction did not occur when the pulse pressure was falling.

This pattern of abnormality occurs in a number of clinical conditions, in particular in diabetes with neuropathy (Sharpey-Shafer \& Taylor, 1960) and in tabes dorsalis (Sharpey-Shafer, 1956), but our patient had no clinical, electrophysiological or pathological evidence of neural involvement. It may result from the administration of such drugs as tranquilizers or barbiturates (Sharpey-Shafer \& Barraclough, 1963) but the patient was not receiving these. It has been reported in primary aldosteronism but not in hyperaldosteronism secondary to renal artery stenosis (Slaton \& Biglieri, 1965); secondary aldosteronism was probably present here (though not due to renal disease) but he did not have Conn's syndrome. An abnormal Valsalva response of this type may also be found in emphysematous subjects (Mills \&
Kattus, 1958) but our patient did not have emphysema. It remains possible that the vascular system was itself unable to respond to normal neurogenic influences although this would imply a far more widespread arteritic process than there was evidence of ; unfortunately this possibility was not studied, in part through reluctance to leave an arterial cannula in the patient's brachial artery for long in view of his active digital arteritis.

A corollary of the Valsalva response here demonstrated is that failure to find a 'square-wave' response does not invalidate the diagnosis of congestive heart failure in a patient with the syndrome of breathlessness, raised jugular venous pressure, congestive hepatomegaly and oedema.

\section{Acknowledgments}

We wish to thank Dr G. S. D. Don for permission to publish this case report and Dr A. Garner for the necropsy findings.

\section{References}

Drachman, D.A. (1963) Neurological complications of Wegener's granulomatosis. Arch. Neurol. (Chic.), 8, 145.

Evans, D.W. \& HalleY, J.B. (1963) Wegener's granulomatosis: Report of a patient surviving four and a half years. J. clin. Path. 16, 215.

Fahey, J.L., Leonard, E., Churg, J. \& Godman, G.C. (1954) Wegener's granulomatosis. Amer. J. Med. 17, 168.

GodmaN, G.C. \& ChURG, J. (1954) Wegener's granulomatosis; pathology and review of literature. Arch. Path. $58,533$.

KLINGER, H. (1931) Grenzformen der periarteritis nodosa. Frankfurt. Z. Path. 42, 455.

Mills, H. \& Kattus, A.A. (1958) The emphysema response to forced straining (Valsalva's maneuver). Circulation, 17, 65.

ShaR PEY-SHAFER, E.P. (1955) Effects of Valsalva's manoeuvre on the normal and failing circulation. Brit. med. J. i, 693.

Shar PEY-Shafer, E.P. (1956) Circulatory reflexes in chronic disease of the afferent nervous system. J. Physiol. (Lond.), 134, 1.

Sharpey-Shafer, E.P. \& Taylor, P.J. (1960) Absent circulatory reflexes in diabetic neuritis. Lancet, $\mathbf{i}, 559$.

Sharpey-Shafer, E.P. \& Barraclough, M.A. (1963) Hypotension from absent circulatory reflexes. Lancet, i, 1121.

Slaton, P.E. \& Biglieri, E.G. (1965) Hypertension and hyperaldosteronism of renal and adrenal origin. Amer. $J$. Med. 38, 324.

Stern, G.M., Hoffbrand, A.V. \& Urich, H. (1965) The peripheral nerves and skeletal muscles in Wegener's granulomatosis: a clinico-pathological study of four cases. Brain, 88, 151.

WALTON, E.W. (1958) Giant cell granuloma of the respiratory tract (Wegener's granulomatosis). Brit. med. J. ii, 265.

WEgENER, F. (1939) Uber eine eigenartige rhinogene Granulomatose mit besonderer Beteilung des Arteriensystems und der Nieren. Beitr. Path. Anat. 102, 36. 